\title{
Relation between outcomes and localisation of p-mTOR expression in gastric cancer
}

\author{
T Murayama', M Inokuchi', , Y Takagi ${ }^{2}$, H Yamada ${ }^{3}$, K Kojima ${ }^{3}$, J Kumagai ${ }^{4}$, T Kawano ${ }^{3}$ and K Sugihara' \\ 'Department of Surgical Oncology, Tokyo Medical and Dental University, 1-5-45, Yushima, Bunkyo, Tokyo I I 3-85 I 9, Japan; ${ }^{2}$ Department of \\ Translational Oncology, Tokyo Medical and Dental University, 1-5-45, Yushima, Bunkyo, Tokyo II 3-85 19, Japan; ${ }^{3}$ Department of Esophagogastric \\ Surgery, Tokyo Medical and Dental University, I-5-45, Yushima, Bunkyo, Tokyo I 13-85 1 9, Japan; ${ }^{4}$ Department of Human Pathology, Tokyo Medical and \\ Dental University, I-5-45, Yushima, Bunkyo, Tokyo I/ 3-85 / 9, Japan
}

The mammalian target of rapamycin (mTOR), a Ser/Thr protein kinase that mediates intracellular signalling related to cell growth, proliferation, and differentiation, has received considerable interest as a possible target for cancer treatment. We evaluated the correlation of mTOR expression with clinicopathological features, outcomes, and the expression of Akt, an upstream regulator of mTOR, in gastric cancer. Tumour samples were obtained from 109 patients with gastric adenocarcinomas who underwent a radical gastrectomy. The expressions of phosphorylated mTOR (p-mTOR) and phosphorylated Akt (p-Akt) in the cytoplasm and in the nucleus were analysed by immunohistochemical staining. Cytoplasmic p-mTOR expression positively correlated with the depth of tumour invasion ( $T I$ vs $T 2-4, P=0.003)$, involved lymph nodes $(P=0.010)$, and tumour stage (I vs $\|-I V, P=0.002)$. In contrast, nuclear $\mathrm{p}$-mTOR expression negatively correlated with these variables $(P<0.00 \mathrm{I},=0.035$, and $<0.00 \mathrm{I})$. Cytoplasmic $\mathrm{p}$-mTOR expression was associated with significantly poorer relapse-free survival (RFS, $P=0.037)$ and overall survival $(O S, P=0.024)$, whereas nuclear $\mathrm{p}$-mTOR expression was associated with better RFS and OS $(P=0.029,0.059)$. Neither cytoplasmic nor nuclear $p$-Akt expression was associated with any clinicopathological factor or with survival. Localisation of p-mTOR may play an important role in tumour progression and outcomes in patients with gastric cancer.

British Journal of Cancer (2009) 100, 782-788. doi:I0. I038/sj.bjc.66049I5 www.bjcancer.com

Published online 17 February 2009

(c) 2009 Cancer Research UK

Keywords: mTOR; Akt; gastric cancer

Gastric cancer is one of the most common malignancies worldwide and ranks as the second leading cause of cancer-related death (Kamangar et al, 2006). Outcomes remain poor in patients with unresectable or metastatic gastric cancer. Their median survival has improved, but is still only about 1 year, even with intensive chemotherapy (Van Cutsem et al, 2006; Cunningham et al, 2008; Koizumi et al, 2008). Anticancer drugs aimed at molecular regulators, including epidermal growth factor receptor (EGFR or HER1), its homologue c-erb-2 (HER2), have been developed and shown to be effective in the breast, lung, and colon cancers (Slamon et al, 2001; Thatcher et al, 2005; Gatzemeier et al, 2007; Sobrero et al, 2008). These drugs have been evaluated in advanced gastric cancer, but two EGFR tyrosine kinase inhibitors were found to be ineffective (Dragovich et al, 2006; Rojo et al, 2006).

The mammalian target of rapamycin (mTOR) has received considerable attention as a possible target for cancer treatment (Huang and Houghton, 2002). mTOR is a Ser/Thr protein kinase that mediates nutrient-dependent intracellular signalling related to cell growth, proliferation, and differentiation. It also functions by integrating extracellular signals such as growth factors. mTOR promotes translation initiation by phosphorylating two targets,

*Correspondence: Dr M Inokuchi; E-mail: m-inokuchi.srg2@tmd.ac.jp Received 17 October 2008; revised 8 January 2009; accepted 12 January 2009; published online 17 February 2009 ribosomal p70S6 kinase (S6K1) and eukaryotic translation initiation factor $4 \mathrm{E}$ binding protein 1 (4E-BP1) (Schmelzle and Hall, 2000; Petroulakis et al, 2006). Rapamycin is a macrolide antibiotic and an immunosuppressive agent that inhibits mTOR. Its antiproliferative effect is mediated through the formation of an active complex. Rapamycin also suppresses angiogenesis by decreasing the production of vascular endothelial growth factor (Guba et al, 2002). mTOR inhibitor has shown promising efficacy in a phase III clinical trial in patients with metastatic renal cell cancer (Motzer et al, 2008). The anticancer effect of RAD001, a rapamycin analogue, has also been shown in advanced gastric cancer (Muro et al, 2008). However, few studies have assessed correlations of mTOR expression in human cancers with either clinocopathological features or outcomes (Zhou et al, 2004; Rajan et al, 2008).

Akt, also known as protein kinase $\mathrm{B}$, is an upstream regulator of mTOR. Three isoforms of Akt have been identified, Akt1, Akt2, and Akt3. Increased expression of Akt isoform was reported in various cancers. Akt is a key intermediate of signalling pathways that regulate cellular processes involved in cell growth, proliferation, survival, and neo-vascularization. Akt has also been shown to play an important role in the chemotherapeutic resistance of tumour cells. The Akt signal transduction pathway is thus considered a promising target for chemotherapy (Altomare and Testa, 2005). However, elevated Akt activity was not associated with tumour progression or poor outcomes in several studies (Tsao et al, 2003; Shah et al, 2005; Chadha et al, 2006). 
Phosphorylated Akt (p-Akt) expression was reported in preneoplastic lesions such as bronchial dysplasia, suggesting that activated Akt has an early role in tumour progression (Tsao et al, 2003; Balsara et al, 2004). Activated Akt has also been frequently observed in gastric cancer (Bellacosa et al, 2005), although two studies showed no correlation of activated Akt with tumour progression or poor survival (Nam et al, 2003; Oki et al, 2005).

Both Akt and mTOR are activated by phosphorylation. This study examined correlations of phosphorylated mTOR (p-mTOR) expression with clinicopathological features, outcomes, and p-Akt expression in gastric cancer. The expressions of $\mathrm{p}-\mathrm{mTOR}$ and p-Akt were evaluated immunohistochemically.

\section{PATIENTS AND METHODS}

\section{Patients}

The study group comprised 109 patients with primary gastric adenocarcinomas who underwent curative gastrectomy (R0) from January 1999 to December 2002 at the Department of Esophagogastric Surgery, Tokyo Medical and Dental University. Each tumour was classified according to the tumour-node-metastasis classification recommended by the International Union against Cancer (UICC). All patients were evaluated for recurrent disease by examination of tumour markers or by diagnostic imaging, including computed tomography, ultrasonography, magnetic resonance imaging, and endoscopy, every 3-6 months. No patient received neoadjuvant therapy, although five patients with stage IV disease received postoperative adjuvant chemotherapy with S-1.

The median follow-up time was 1953 days (range: 50-3197). Recurrent disease was diagnosed in 29 patients $(27 \%)$ and was the cause of death in 28 of these patients.

\section{Immunostaining of p-mTOR and p-Akt}

Immunohistochemical staining was carried out by the streptavidin-biotin method using a Histofine SAB-PO kit (Nichirei Co., Tokyo, Japan). Polyclonal rabbit anti-human antibodies against p-mTOR $\left(\operatorname{Ser}^{2448}\right)$ and p-Akt $\left(\operatorname{Ser}^{473}\right)$ were purchased from Cell Signaling Technology, Inc. (Beverly, MA, USA). All available haematoxylin and eosin stained slides of the surgical specimens were reviewed. For each case, representative paraffin blocks were selected for immunohistochemical studies. Three-micrometerthick sections were cut from formalin-fixed, paraffin-embedded tissue blocks. After deparaffinisation and rehydration, antigen retrieval treatment was carried out at $121^{\circ} \mathrm{C}$ (autoclave) for $5 \mathrm{~min}$ in $10 \mathrm{nmoll}^{-1}$ sodium citrate buffer $(\mathrm{pH} 9.0)$, followed by treatment with $3 \%$ hydrogen peroxide for $15 \mathrm{~min}$ to quench endogenous peroxidase activity. Nonspecific binding was blocked by treating the slides with 5\% EzBlock (including 5\% normal goat serum and $0.1 \%$ Tween 20 ) for $60 \mathrm{~min}$ at room temperature. The slides were incubated with primary antibodies including p-mTOR (dilution $1: 50)$ and p-Akt $(1: 50)$ overnight at $4^{\circ} \mathrm{C}$. Immunodetection was performed by the conventional streptavidin-biotin method with a Nichirei SAB-PO kit. The slides were counterstained with $1 \%$ Mayer's haematoxylin.

The p-mTOR and p-Akt levels were classified into three groups based on both staining intensity and positive frequency according to the scoring method described by (Zhou et al, 2004). Tumours in which $<10 \%$ of cells were weakly stained were scored as 0 , tumours in which $>10 \%$ of cells were weakly stained or $<20 \%$ of cells were strongly stained were scored as 1 , and tumours in which $>20 \%$ of cells were strongly stained were scored as 2 . A score of ' 1 ' or ' 2 ' was defined as 'positive' expression, and a score of ' 0 ' was defined as 'negative' expression. We counted stained cells under a microscope to derive the scores. Cytoplasmic staining and nuclear staining were evaluated separately.

\section{Statistical analysis}

The $\chi^{2}$ test was used to test possible associations between the expression of $\mathrm{p}$-mTOR or $\mathrm{p}$-Akt and clinicopathological factors. It was also used to assess correlations between p-mTOR and p-Akt expressions. The Mann-Whitney $U$-test was used to analyse the relation between each type of expression and age. Kaplan-Meier curves were plotted to assess the effects of p-mTOR and p-Akt expressions on relapse-free survival (RFS) and overall survival (OS). Survival curves were compared using the log-rank test. $P$-values of 0.05 or less were considered to indicate statistical significance. Multivariate proportional Cox models were used to assess the prognostic significance of p-mTOR and p-Akt expressions and of several clinicopathological factors. Statistical analysis was carried out with the use of SPSS Base, version 11.0 and SPSS Advanced Models, version 11.0 (SPSS Inc, Chicago, IL, USA) software.

\section{RESULTS}

Cytoplasmic expression of p-mTOR was found in 69 (63\%) of all tumours, and nuclear expression was found in $33(30 \%)$. Cytoplasmic expression of p-Akt was observed in 94 (86\%) tumours, and nuclear expression was observed in 45 (43\%). No $\mathrm{p}$-mTOR or p-Akt staining was detected in normal gastric mucosa (Figure 1).

There was no correlation between p-mTOR and p-Akt expression, but many tumours with cytoplasmic p-mTOR expression showed cytoplasmic p-Akt expression. Nearly all the tumours with nuclear p-mTOR or p-Akt expression showed cytoplasmic expression of the same molecule (Table 1).

The cytoplasmic expression of p-mTOR positively correlated with the depth of tumour invasion (T1 vs T2 $-4 ; P=0.003$ ), lymph node involvement $(P=0.010)$, and UICC stage (I vs II-IV; $P=0.002)$. Nuclear $\mathrm{p}-\mathrm{mTOR}$ expression negatively correlated with the depth of tumour invasion, lymph node involvement, and the UICC stage $(P<0.001,=0.035$ and $<0.001$, respectively). Neither cytoplasmic nor nuclear p-Akt expression was related to any clinicopathological factor. The rates of cytoplasmic p-mTOR and p-Akt expressions were slightly, but not significantly, higher among younger patients (Tables 2 and 3 ).

Patients with cytoplasmic p-mTOR expression had significantly shorter RFS and OS than those without cytoplasmic p-mTOR expression ( $P=0.037,0.024$, respectively). In contrast, nuclear p-mTOR expression was associated with significantly longer RFS $(P=0.029)$, as well as with slightly, but not significantly, longer OS $(P=0.053)$. We next classified patients into the following four subgroups according to the p-mTOR expression of their tumours and analysed survival: patients with positive expressions of both cytoplasmic and nuclear p-mTOR (group A), positive expression of only cytoplasmic p-mTOR (B), positive expression of only nuclear p-mTOR (C), and negative expressions of both cytoplasmic and nuclear p-mTOR (D). Survival was significantly poorer in group $\mathrm{B}$ than in the other three groups ( $v$ s group $\mathrm{A}, \mathrm{C}$, and $\mathrm{D} ; P=0.031,0.049$, and 0.036 , respectively). There were no other significant differences in this analysis. In contrast, neither cytoplasmic nor nuclear expression of p-Akt was associated with either RFS $(P=0.74,0.40$, respectively) or OS $(P=0.77,0.65$, respectively) (Figure 2).

The prognostic relevance of $\mathrm{p}$-mTOR and p-Akt expression was assessed using a multivariate proportional-hazards model adjusted for established clinical prognostic factors (i.e., depth of tumour invasion, lymph node involvement, histological type, sex, and age) (Table 4). The depth of tumour invasion and lymph node involvement were independent prognostic factors (hazard ratio $(\mathrm{HR})=6.62,95 \%$ confidence interval $(\mathrm{CI}) 1.32-33.4, P=0.022$; $\mathrm{HR}=3.08, \quad 95 \%$ CI 1.04-9.21, $P=0.043$, respectively), but 

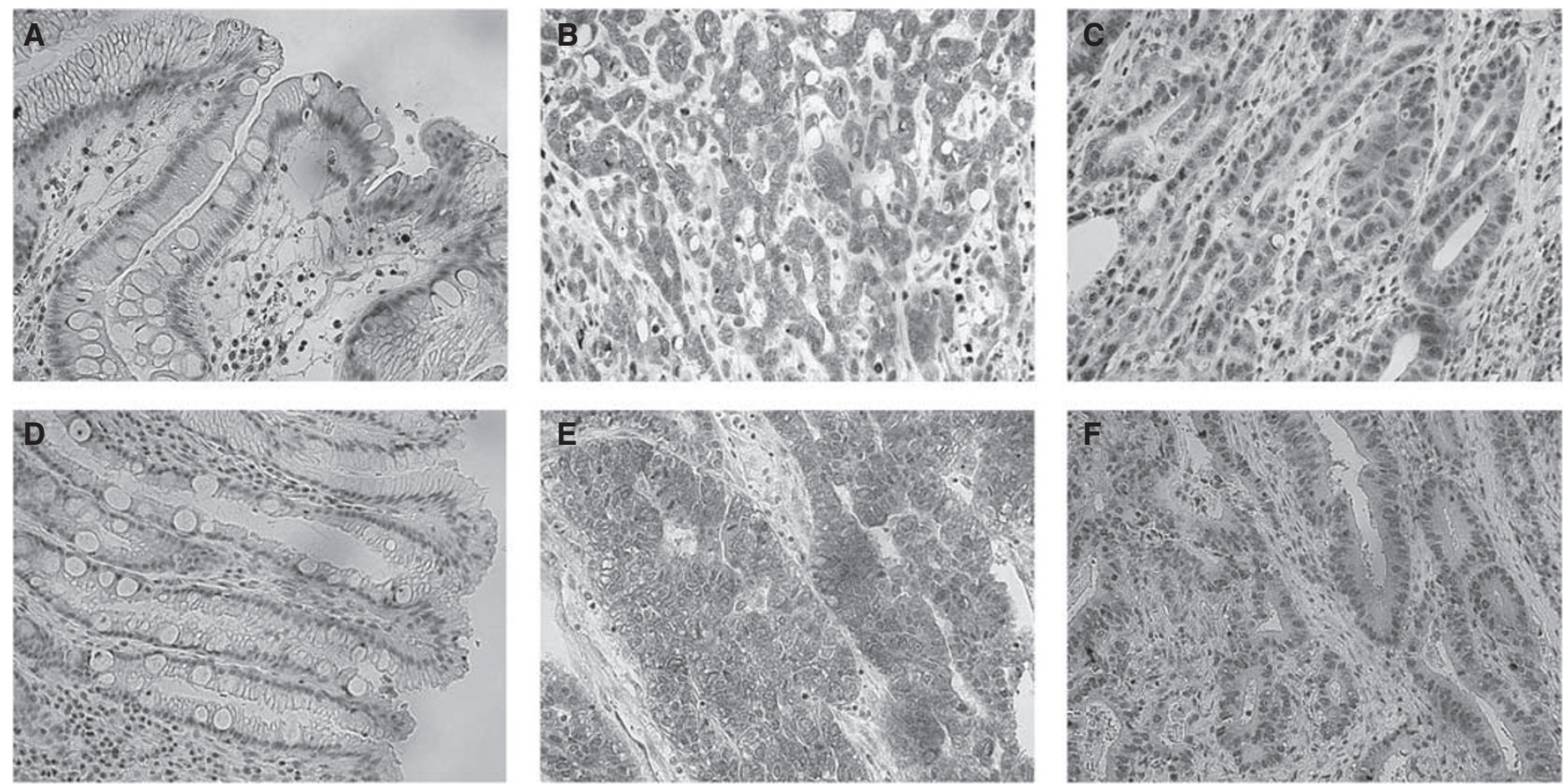

Figure I No expression of p-mTOR (A) or p-Akt (D) was detected in normal gastric mucosa. Representative gastric carcinomas showing immunostaining for p-mTOR predominantly in the cytoplasm $(\mathbf{B})$ and predominantly in the nucleus $(\mathbf{C})$; immunostaining for p-Akt predominantly in the cytoplasm $(\mathbf{E})$ and predominantly in the nucleus $(\mathbf{F})$, magnification; $\times 400$.

Table I Correlations among the cytoplasmic and nuclear expressions of p-mTOR and p-Akt

\begin{tabular}{|c|c|c|c|c|c|c|c|c|c|}
\hline & \multicolumn{2}{|c|}{ p-mTOR (nucleus) } & $P$-value & \multicolumn{2}{|c|}{ p-Akt (cytoplasmic) } & $P$-value & \multicolumn{2}{|c|}{ p-Akt (nucleus) } & $P$-value \\
\hline Negative & 34 & 6 & 0.015 & 9 & 31 & 0.084 & 27 & 13 & 0.16 \\
\hline Positive & 42 & 27 & & 6 & 63 & & 37 & 32 & \\
\hline \multicolumn{10}{|c|}{ p-mTOR (nucleus) } \\
\hline \multicolumn{10}{|c|}{ p-Akt (cytoplasmic) } \\
\hline Negative & & & & & & & 15 & 0 & $<0.001$ \\
\hline Positive & & & & & & & 49 & 45 & \\
\hline
\end{tabular}

Abbreviations: $\mathrm{p}-\mathrm{Akt}=$ phosphorylated Akt; $\mathrm{p}-\mathrm{mTOR}=$ phosphorylated $\mathrm{mTOR}$.

cytoplasmic expression of p-mTOR was not independent $(\mathrm{HR}=1.42,95 \%$ CI $0.51-3.97, P=0.51)$.

\section{DISCUSSION}

Our study showed that p-mTOR expression was significantly related to tumour progression and outcomes in patients with gastric cancer. Interestingly, the cytoplasmic expression of p-mTOR positively correlated with factors related to tumour progression and poor outcomes in gastric cancer, whereas the nuclear expression of p-mTOR negatively correlated with such factors. This finding suggests that changes in the localisation of p-mTOR may be involved in tumour progression. Other investigators reported that $\mathrm{m}$-TOR is mainly localised in the cytoplasm (Janus et al, 2005; Bachmann et al, 2006), although a small fraction of mTOR is found at a steady state in the nucleus in both normal and malignant cells (Zhang et al, 2002). mTOR is part of two distinct complexes: mTORC1 containing raptor and a mammalian orthologue of yeast Lst8p (mLST8; also known as G $\beta \mathrm{L}$ ), and mTORC2 containing rictor, mLST8, and $\sin 1$ (also known as mitogen-activated protein-kinase-associated protein 1) (Sarbassov et al, 2005; Petroulakis et al, 2006; Rosner and Hengstschläger, 2008). mTORC1 was predominantly found in the cytoplasm of fibroblast cells (Rosner and Hengstschläger, 2008), although its distribution was not clear in cancer cells. mTORC1 pathway promotes cell growth and proliferation by activating mRNA translation and ribosome biogenesis and by inhibiting autophagy through activation of $\mathrm{S} 6 \mathrm{~K} 1$ and inhibition of 4E-BP1. S6K1 drives translation of 5 TOP (terminal oligopyrimidine tract) mRNAs, and 4E-BP1 inhibits the mRNA cap-binding protein elF4E (Schmelzle and Hall, 2000). 4E-BP1 and S6K1 were detected exclusively in the cytoplasm of cancer cells (Zhang et al, 2002). We suggest that increased cytoplasmic mTORC1 complex may activate signalling to 
Table 2 Correlations between p-mTOR expression and clinicopathological factors

\begin{tabular}{|c|c|c|c|c|c|c|c|}
\hline & $\begin{array}{c}\text { All } \\
n(\%)\end{array}$ & \multicolumn{2}{|c|}{ Cytoplasmic p-mTOR } & $P$-value & \multicolumn{2}{|c|}{ Nuclear p-mTOR } & $P$-value \\
\hline Male & $77(7 \mathrm{I})$ & 26 & 51 & 0.33 & 54 & 23 & $>0.99$ \\
\hline Female & $32(29)$ & 14 & 18 & & 22 & 10 & \\
\hline Median age (range) & $65(35-85)$ & $62(35-79)$ & $66(43-85)$ & 0.079 & $65(35-85)$ & $64(5|-8|)$ & 0.77 \\
\hline \multicolumn{8}{|l|}{ Depth of invasion } \\
\hline $\mathrm{T} 2 / 3 / 4$ & $41(38) / 20(18) / 4(4)$ & 16 & 48 & & 53 & 11 & \\
\hline \multicolumn{8}{|l|}{ LN metastasis } \\
\hline Positive $(\mathrm{NI} / 2 / 3)$ & $33(30) / 17(16) / 3(3)$ & 13 & 40 & 0.010 & 42 & 11 & 0.035 \\
\hline Negative (NO) & $56(5 \mathrm{I})$ & 27 & 29 & & 34 & 22 & \\
\hline \multicolumn{8}{|l|}{ Stage } \\
\hline Negative & $80(73)$ & 34 & 46 & & 51 & 29 & \\
\hline \multicolumn{8}{|l|}{ Histopathology } \\
\hline Intestinal & $40(37)$ & 13 & 27 & 0.49 & 25 & 15 & 0.21 \\
\hline Diffuse & $69(63)$ & 27 & 42 & & 51 & 18 & \\
\hline
\end{tabular}

Abbreviations: $L N$ metastasis $=$ lymph node metastasis; $\mathrm{p}-\mathrm{mTOR}=$ phosphorylated $\mathrm{mTOR}$.

Table 3 Correlations between p-Akt expression and clinicopathological factors

\begin{tabular}{|c|c|c|c|c|c|c|c|}
\hline & \multirow{2}{*}{$\begin{array}{c}\text { All } \\
n(\%)\end{array}$} & \multicolumn{2}{|c|}{ Cytoplasmic p-Akt } & \multirow[b]{2}{*}{$P$-value } & \multicolumn{2}{|c|}{ Nuclear p-Akt } & \multirow[b]{2}{*}{$P$-value } \\
\hline & & Negative & Positive & & Negative & Positive & \\
\hline \multicolumn{8}{|l|}{ Sex } \\
\hline Male & $77(7 \mid)$ & 9 & 68 & 0.50 & 45 & 32 & 0.93 \\
\hline Female & $32(29)$ & 6 & 26 & & 19 & 13 & \\
\hline Median age (range) & $65(35-85)$ & $58(35-72)$ & $65(43-85)$ & 0.060 & $64(35-82)$ & $66(43-85)$ & 0.81 \\
\hline \multicolumn{8}{|l|}{ Depth of invasion } \\
\hline $\mathrm{T} 2 / 3 / 4$ & $41(38) / 20(18) / 4(4)$ & 8 & 56 & & 38 & 26 & \\
\hline \multicolumn{8}{|l|}{ LN metastasis } \\
\hline Positive $(\mathrm{NI} / 2 / 3)$ & $33(30) / 17(16) / 3(3)$ & 6 & 47 & 0.66 & 30 & 23 & 0.66 \\
\hline Negative (NO) & $56(5 \mathrm{I})$ & 9 & 47 & & 34 & 22 & \\
\hline \multicolumn{8}{|l|}{ Stage } \\
\hline Positive & $29(27)$ & 4 & 25 & $>0.99$ & 15 & 14 & 0.37 \\
\hline Negative & $80(73)$ & 11 & 69 & & 49 & 31 & \\
\hline \multicolumn{8}{|l|}{ Histopathology } \\
\hline Intestinal & 40 (37) & 4 & 36 & 0.57 & 24 & 16 & 0.84 \\
\hline Diffuse & $69(63)$ & 11 & 58 & & 40 & 29 & \\
\hline
\end{tabular}

Abbreviations: $L N$ metastasis = lymph node metastasis; $\mathrm{p}$-Akt = phosphorylated Akt.

cytoplasmic S6K1 and 4E-BP1 and contribute to tumour progression, although $4 \mathrm{E}-\mathrm{BP} 1$ and S6K1 were not investigated in this study. In addition, mTOR shuttles between the nucleus and the cytoplasm (Zhang et al, 2002; Bachmann et al, 2006). The nuclear import of mTOR has an important role in activating its cytoplasmic signalling (Bachmann et al, 2006). However, the mechanism of nuclear transportation of $\mathrm{mTOR}$ and the function of nuclear mTOR remain unclear. Only substrates activated by nuclear p-mTOR may not be adequate to promote tumour growth because nuclear p-mTOR was found more frequently in early-stage disease. On the other hand, mTORC2 is required for Akt phosphorylation on Ser473 to achieve full activation (Sarbassov et al, 2005). Activated Akt was not related to either tumour progression or outcomes in this study, therefore, mTORC2 also 

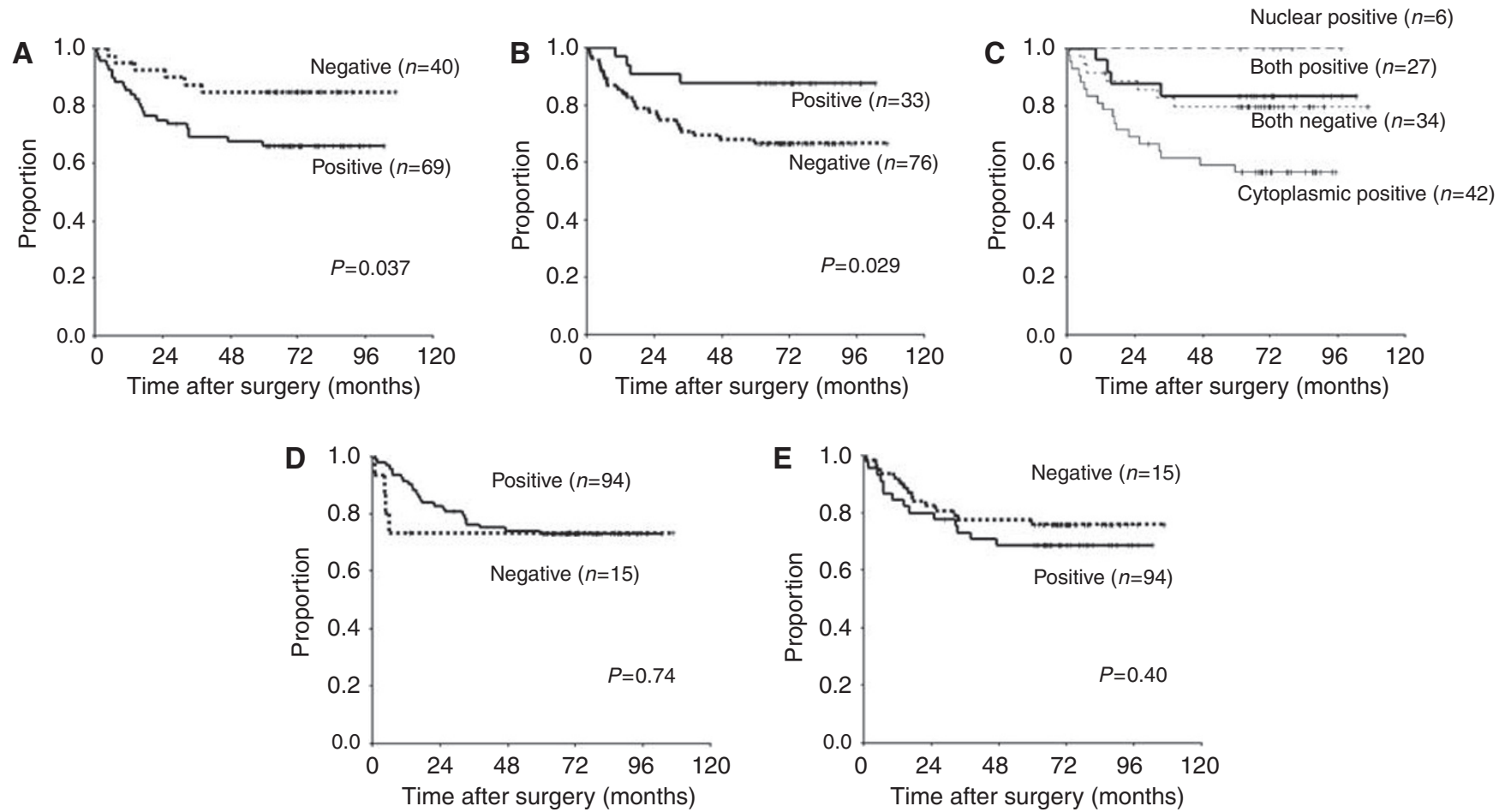

Figure 2 Kaplan-Meier curves for the relapse-free survival of patients with expression of cytoplasmic p-mTOR (A), nuclear p-mTOR (B), cytoplasmic p-Akt (D), and both nuclear p-Akt and cytoplasmic p-Akt (E). Kaplan-Meier curves for the four subgroups classified according to p-mTOR expression are shown in $(\mathbf{C})$.

Table 4 Prognostic factors in a multivariate Cox proportional-hazards regression model

\begin{tabular}{lccc}
\hline & HR & $\mathbf{9 5 \%} \mathbf{C l}$ & P-value \\
\hline Age & 0.98 & $0.94-10.2$ & 0.35 \\
Sex; female vs male & 1.23 & $0.49-3.11$ & 0.66 \\
Pathological type; intestinal vs diffuse & 0.88 & $0.38-2.05$ & 0.77 \\
Depth of invasion; TI vs T2-4 & 6.62 & $1.32-33.4$ & 0.022 \\
Involved lymph nodes & 3.09 & $1.04-9.21$ & 0.043 \\
Cytoplasmic p-mTOR & 1.42 & $0.51-3.97$ & 0.51 \\
Nuclear p-mTOR & 0.57 & $0.18-1.77$ & 0.33 \\
Cytoplasmic p-Akt & 0.35 & $0.11-1.16$ & 0.086 \\
Nuclear p-Akt & 0.16 & $0.80-3.99$ & 0.16 \\
\hline
\end{tabular}

Abbreviations: $\mathrm{Cl}=$ confidence interval; $\mathrm{HR}=$ hazard ratio; $\mathrm{p}$-Akt = phosphorylated Akt; $\mathrm{p}-\mathrm{mTOR}=$ phosphorylated mTOR.

may not be related to these variables. Rosner and Hengstschläger provided evidence that cytoplasmic raptor had a higher affinity for mTOR than nuclear raptor (Rosner and Hengstschläger, 2008). They proposed distinct mechanisms for regulation of mTOR in the cytoplasm and the nucleus, and such mechanisms may be associated with clinical outcomes.

In this study, $31 \%$ of tumours showed no activation of p-mTOR, despite of a high frequency of activated Akt. The rate of negative p-mTOR in gastric cancer was similar to that in another study (Lang et al, 2007). That study also showed that negative expression of p-mTOR was observed in normal gastric mucosa, whereas its positive expression was more frequent in advanced disease. In tumours without $\mathrm{p}$-mTOR expression, another signalling pathway, such as Erk, may be activated. In pancreatic cancer, high expression of phosphorylated Erk was associated with shorter survival, whereas high expression of p-Akt was associated with longer survival (Chadha et al, 2006). In breast cancer, p-mTOR expression is predominantly detected in the cytoplasm and is significantly associated with short RFS, but does not correlate with any clinicopathological factors, including stage, histological grade, and lymph node involvement (Zhou et al, 2004). Rajan et al found that p-mTOR expression is unrelated to survival in pancreatic cancer (Rajan et al, 2008). Boone et al reported that p-mTOR expression is only associated with a lesser degree of tumour differentiation (Boone et al, 2008). To our knowledge, however, no earlier study has assessed nuclear p-mTOR expression. Our study is the first to show that different localisation of mTOR expression (i.e., cytoplasmic $v s$ nuclear) was associated with different outcomes in patients with cancer.

Phosphorylated Akt activates many downstream targets, including mTOR, and is thought to play a role in tumour progression. However, earlier studies of Akt expression in human cancers have yielded conflicting results. In pancreatic cancer, one study showed a correlation between higher p-Akt expression and shorter survival (Yamamoto et al, 2004), whereas another study showed the opposite (Chadha et al, 2006). Higher p-Akt expression was associated with poor outcomes in breast cancer (Zhou et al, 2004), and with lymph node metastasis or advanced disease stage in colorectal cancer (Itoh et al, 2002). On the other hand, increased p-Akt expression correlated with favourable outcomes in non-small-cell lung cancer (Shah et al, 2005). In gastric cancer, Nam et al reported that tumours with p-Akt expression are associated with the absence of lymph node metastasis and with longer survival in early-stage disease (Nam et al, 2003). In our study, p-Akt expression was frequently observed in both early and advanced gastric cancers and was not related to clinicopathological factors or survival. These discrepancies may be partly explained by differences in the type of cancer studied, in the system used to classify p-Akt staining, or in the expression of downstream targets of p-AKt, such as mTOR.

Several inhibitors of mTOR kinase have been evaluated in various solid tumours, including renal, breast, pancreatic, and endometrial cancer, and their anticancer efficacy has been shown (Janus et al, 2005). The mTORC1 complex is sensitive to rapamycin (Janus et al, 2005; Sarbassov et al, 2005). As mTORC1 complex is mainly found in the cytoplasm, tumours with 
cytoplasmic expression of mTOR may be more sensitive to mTOR inhibitors than those with nuclear expression of mTOR. In addition, Akt requires mTORC2 to achieve its full activation, suggesting that inhibition of mTORC2 is essential for preventing the progression of tumours with highly activated Akt/mTOR signalling.
In conclusion, cytoplasmic p-mTOR expression was associated with tumour progression and poor survival in gastric cancer; the opposite results were obtained for nuclear p-mTOR expression. Localisation of p-mTOR might thus be critical to tumour progression and outcomes in patients with gastric cancer.

\section{REFERENCES}

Altomare DA, Testa JR (2005) Perturbations of the AKT signaling pathway in human cancer. Oncogene 24: $7455-7464$

Bachmann RA, Kim JH, Wu AL, Park IH, Chen J (2006) A nuclear transport signal in mammalian target of rapamycin is critical for its cytoplasmic signaling to S6 kinase 1. J Biol Chem 281: 7357-7363

Balsara BR, Pei J, Mitsuuchi Y, Page R, Klein-Szanto A, Wang H, Unger M, Testa JR (2004) Frequent activation of AKT in non-small cell lung carcinomas and preneoplastic bronchial lesions. Carcinogenesis 25: 2053-2059

Bellacosa A, Kumar CC, Di Cristofano A, Testa JR (2005) Activation of AKT kinases in cancer: implications for therapeutic targeting. Adv Cancer Res 94: $29-86$

Boone J, Ten Kate FJ, Offerhaus GJ, van Diest PJ, Rinkes IH, van Hillegersberg R (2008) mTOR in squamous cell carcinoma of the oesophagus: a potential target for molecular therapy? J Clin Pathol 61: 909-913

Chadha KS, Khoury T, Yu J, Black JD, Gibbs JF, Kuvshinoff BW, Tan D, Brattain MG, Javle MM (2006) Activated Akt and Erk expression and survival after surgery in pancreatic carcinoma. Ann Surg Oncol 13: 933-939

Cunningham D, Starling N, Rao S, Iveson T, Nicolson M, Coxon F, Middleton G, Daniel F, Norman AR, Upper Gastrointestinal Clinical Studies Group of the National Cancer Research Institute of the United Kingdom (2008) Capecitabine and oxaliplatin for advanced esophagogastric cancer. $N$ Engl J Med 358: $36-46$

Dragovich T, McCoy S, Fenoglio-Preiser CM, Wang J, Benedetti JK, Baker AF, Hackett CB, Urba SG, Zaner KS, Blanke CD, Abbruzzese JL (2006) Phase II trial of erlotinib in gastroesophageal junction and gastric adenocarcinomas: SWOG 0127. J Clin Oncol 24: 4922-4927

Gatzemeier U, Pluzanska A, Szczesna A, Kaukel E, Roubec J, De Rosa F, Milanowski J, Karnicka-Mlodkowski H, Pesek M, Serwatowski P, Ramlau R, Janaskova T, Vansteenkiste J, Strausz J, Manikhas GM, Von Pawel J (2007) Phase III study of erlotinib in combination with cisplatin and gemcitabine in advanced non-small-cell lung cancer: the Tarceva Lung Cancer Investigation Trial. J Clin Oncol 25: 1545-1552

Guba M, von Breitenbuch P, Steinbauer M, Koehl G, Flegel S, Hornung M, Bruns CJ, Zuelke C, Farkas S, Anthuber M, Jauch KW, Geissler EK (2002) Rapamycin inhibits primary and metastatic tumor growth by antiangiogenesis: involvement of vascular endothelial growth factor. Nat Med 8: $128-135$

Huang S, Houghton PJ (2002) Inhibitors of mammalian target of rapamycin as novel antitumor agents: from bench to clinic. Curr Opin Investig Drugs 3: $295-304$

Itoh N, Semba S, Ito M, Takeda H, Kawata S, Yamakawa M (2002) Phosphorylation of Akt/PKB is required for suppression of cancer cell apoptosis and tumor progression in human colorectal carcinoma. Cancer 94: $3127-3134$

Janus A, Robak T, Smolewski P (2005) The mammalian target of the rapamycin (mTOR) kinase pathway: its role in tumourigenesis and targeted antitumour therapy. Cell Mol Biol Lett 10: 479-498

Kamangar F, Dores GM, Anderson WF (2006) Patterns of cancer incidence, mortality, and prevalence across five continents: defining priorities to reduce cancer disparities in different geographic regions of the world. J Clin Oncol 24: $2137-2150$

Koizumi W, Narahara H, Hara T, Takagane A, Akiya T, Takagi M, Miyashita K, Nishizaki T, Kobayashi O, Takiyama W, Toh Y, Nagaie T, Takagi S, Yamamura Y, Yanaoka K, Orita H, Takeuchi M (2008) S-1 plus cisplatin versus S-1 alone for first-line treatment of advanced gastric cancer (SPIRITS trial): a phase III trial. Lancet Oncol 9: 215-221

Lang SA, Gaumann A, Koehl GE, Seidel U, Bataille F, Klein D, Ellis LM, Bolder U, Hofstaedter F, Schlitt HJ, Geissler EK, Stoeltzing O (2007) Mammalian target of rapamycin is activated in human gastric cancer and serves as a target for therapy in an experimental model. Int J Cancer 120: $1803-1810$
Motzer RJ, Escudier B, Oudard S, Hutson TE, Porta C, Bracarda S, Grünwald V, Thompson JA, Figlin RA, Hollaender N, Urbanowitz G, Berg WJ, Kay A, Lebwohl D, Ravaud A, RECORD-1 Study Group (2008) Efficacy of everolimus in advanced renal cell carcinoma: a double-blind, randomised, placebo-controlled phase III trial. Lancet 372: 427-429

Muro K, Boku N, Yamada Y, Nishina T, Doi T, Takiuchi H, Tajima T, Takahashi A, Fujita Y, Ohtsu A (2008) Multicenter phase II study of RAD001 for previously treated metastatic gastric cancer (MGC): preliminary results. Proc Am Soc Clin Oncol 26: 4541

Nam SY, Lee HS, Jung GA, Choi J, Cho SJ, Kim MK, Kim WH, Lee BL (2003) Akt/PKB activation in gastric carcinomas correlates with clinicopathologic variables and prognosis. APMIS 111: 1105-1113

Oki E, Baba H, Tokunaga E, Nakamura T, Ueda N, Futatsugi M, Mashino K, Yamamoto M, Ikebe M, Kakeji Y, Maehara Y (2005) Akt phosphorylation associates with LOH of PTEN and leads to chemoresistance for gastric cancer. Int J Cancer 117: 376-380

Petroulakis E, Mamane Y, Le Bacquer O, Shahbazian D, Sonenberg N (2006) mTOR signaling: implications for cancer and anticancer therapy. Br J Cancer 94: 195 - 199

Rajan A, Tolocica I, El-Zammar O, Chittoria N, Singh M, Newman N, Gajra A (2008) mTOR expression in pancreatic adenocarcinoma and its correlation with survival. Proc Am Soc Clin Oncol 26: 22169

Rojo F, Tabernero J, Albanell J, Van Cutsem E, Ohtsu A, Doi T, Koizumi W, Shirao K, Takiuchi H, Ramon y Cajal S, Baselga J (2006) Pharmacodynamic studies of gefitinib in tumor biopsy specimens from patients with advanced gastric carcinoma. J Clin Oncol 24: 4309-4316

Rosner M, Hengstschläger M (2008) Cytoplasmic and nuclear distribution of the protein complexes $\mathrm{mTORC} 1$ and $\mathrm{mTORC} 2$ : rapamycin triggers dephosphorylation and delocalisation of the mTORC2 components rictor and sin1. Hum Mol Genet 17: 2934-2948

Sarbassov DD, Guertin DA, Ali SM, Sabatini DM (2005) Phosphorylation and regulation of $\mathrm{Akt} / \mathrm{PKB}$ by the rictor-mTOR complex. Science 307: $1098-1101$

Schmelzle T, Hall MN (2000) TOR, a central controller of cell growth. Cell 103: $253-262$

Shah A, Swain WA, Richardson D, Edwards J, Stewart DJ, Richardson CM, Swinson DE, Patel D, Jones JL, O'Byrne KJ (2005) Phospho-akt expression is associated with a favorable outcome in non-small cell lung cancer. Clin Cancer Res 11: 2930-2936

Slamon DJ, Leyland-Jones B, Shak S, Fuchs H, Paton V, Bajamonde A, Fleming T, Eiermann W, Wolter J, Pegram M, Baselga J, Norton L (2001) Use of chemotherapy plus a monoclonal antibody against HER2 for metastatic breast cancer that overexpresses HER2. $N$ Engl J Med 344: $783-792$

Sobrero AF, Maurel J, Fehrenbacher L, Scheithauer W, Abubakr YA, Lutz MP, Vega-Villegas ME, Eng C, Steinhauer EU, Prausova J, Lenz HJ, Borg C, Middleton G, Kröning H, Luppi G, Kisker O, Zubel A, Langer C, Kopit J, Burris III HA (2008) EPIC: phase III trial of cetuximab plus irinotecan after fluoropyrimidine and oxaliplatin failure in patients with metastatic colorectal cancer. J Clin Oncol 26: 2311-2319

Thatcher N, Chang A, Parikh P, Rodrigues Pereira J, Ciuleanu T, von Pawel J, Thongprasert S, Tan EH, Pemberton K, Archer V, Carroll K (2005) Gefitinib plus best supportive care in previously treated patients with refractory advanced non-small-cell lung cancer: results from a randomised, placebo-controlled, multicentre study (Iressa Survival Evaluation in Lung Cancer). Lancet 366: 1527-1537

Tsao AS, McDonnell T, Lam S, Putnam JB, Bekele N, Hong WK, Kurie JM (2003) Increased phospho-AKT (Ser(473)) expression in bronchial dysplasia: implications for lung cancer prevention studies. Cancer Epidemiol Biomarkers Prev 12: 660-664

Van Cutsem E, Moiseyenko VM, Tjulandin S, Majlis A, Constenla M, Boni C, Rodrigues A, Fodor M, Chao Y, Voznyi E, Risse ML, Ajani JA, V325 Study Group (2006) Phase III study of docetaxel and cisplatin plus fluorouracil compared with cisplatin and fluorouracil as first-line 
therapy for advanced gastric cancer: a report of the V325 Study Group. J Clin Oncol 24: 4991-4997

Yamamoto S, Tomita Y, Hoshida Y, Morooka T, Nagano $\mathrm{H}$, Dono K, Umeshita K, Sakon M, Ishikawa O, Ohigashi H, Nakamori S, Monden M, Aozasa K (2004) Prognostic significance of activated Akt expression in pancreatic ductal adenocarcinoma. Clin Cancer Res 10: $2846-2850$

Zhang X, Shu L, Hosoi H, Murti KG, Houghton PJ (2002) Predominant nuclear localization of mammalian target of rapamycin in normal and malignant cells in culture. J Biol Chem 277: 28127-28134

Zhou X, Tan M, Stone Hawthorne V, Klos KS, Lan KH, Yang Y, Yang W, Smith TL, Shi D, Yu D (2004) Activation of the Akt/mammalian target of rapamycin/4E-BP1 pathway by ErbB2 overexpression predicts tumor progression in breast cancers. Clin Cancer Res 10: 6779-6788 